\title{
Long-term Changes in Annual Precipitation and Monsoon Seasonal Characteristics in Myanmar
}

\section{Win Win Zin ${ }^{1 *}$ and Martine Rutten ${ }^{2}$}

${ }^{1}$ Yangon Technological University, Insein Rd, Yangon, Myanmar

${ }^{2}$ Delft University of Technology, Stevinweg 1, 2600 GA Delft, The Netherlands

\begin{abstract}
Understanding the spatial and temporal precipitation patterns is essential for climate change and water resources management in Myanmar. In this study, trend detection was performed on historical precipitation series with a maximum length of 49 years. The Mann-Kendall non-parametric test and the Pettitt test were applied to detect trends and step changes in annual total precipitation, annual maximum precipitation and monsoon onset and withdrawal dates. Abrupt changes in trend detection were taken into account and trend analyses on the segments of records discriminated by change points were performed. For 17 out of 82 stations dominated significant trends in annual total precipitation were revealed when ignoring the presence of change points. Upward trends were mainly detected in the southern and coastal parts of the country and downward trends were mainly detected in the central part of the country. However, only two significant trends were detected in the subseries divided by change point. It is noticed that monsoon withdrawal dates have shifted to be early.
\end{abstract}

Keywords: Mann-Kendall; Myanmar; Precipitation; Pettitt; Trend

\section{Introduction}

Understanding precipitation patterns is vital for water resources management in Myanmar. People's well-being and income in this agriculturally dominated country particularly rely on the availability of sufficient water [1]. Flooding due to too much water is the most commonly occurring form of natural disaster in Myanmar, affecting yearly over $2,000,000$ people [2]. Spatiotemporal variation in precipitation in Myanmar is large. The annual total average precipitation varies from 900 $\mathrm{mm}$ in the central to about $4600 \mathrm{~mm}$ in the south (See Figure 1). Most precipitation falls within the monsoon period from May till October. Changes in precipitation will cause changes in availability and excess of water and are important to anticipate in water resources management, particularly in a rapid developing county such as Myanmar.

There seems a direct influence of global warming on precipitation and changes in precipitation patterns are expected to occur globally [3]. In 2000, Sen et al. [4] reported, based on an analysis of station data over the period 1947 to 1970 , no significant trends in precipitation in Myanmar. More recent research showed some indication of changes in precipitation patterns. Based on gridded precipitation products and reanalysis data [5] report doubling in May precipitation in Myanmar over the period from 1979 to 2010 . According to climate projections Myanmar precipitation patterns are expected to change. The multimodel (of 20 CMIP3) mean suggests enhanced precipitation over Myanmar [6]. The mean annual precipitation in the Bago river basin is projected to increase by $90 \mathrm{~mm}$ to $115 \mathrm{~mm}$ by 2050 [7]. Yet, statistical evidence of changes occurring in station data in Myanmar is still missing.

We here present an analysis of trends in precipitation Myanmar based on a set of 82 station long term time series and thereby extend Sen et al. [4] work to check if changes can be detected if more recent data is included. We performed the trend analysis first by assuming linear trends and ignoring change points and second by considering change points. In addition, we present a trend analysis and change point analysis of monsoon onset and withdrawal. Finally, we discuss to which extent detected changes can be attributed to climate change and land use changes.

\section{Materials and Methods}

Precipitation time series of 82 stations were tested for trends in total annual precipitation and maximum annual precipitation. The MannKendall non-parametric test, which is widely used [8-12] to detect trends, was applied. Trend analysis is often disturbed by the presence of change points. Therefore, the trend is analysis was followed by change point analysis as suggested by Villarini et al. [13]. The change per unit time was estimated by applying Sen's estimator of slope and the Pettitt test was done to detect step changes. In addition, trends in onset, withdrawal and duration of the monsoon were analyzed. We used nonparametric methods and removed serial correlation to avoid false trend detection due to persistence in and/or heave tailed probability density distributions of the time series.

\section{Stations}

The monitoring network used in this study (Figure 2) consists of 82 precipitation stations with a maximum sample size of 49 years spanning from 1967 to 2015. The monitoring network is assumed to reflect the meteorological conditions. The length of data set in this study suffices the minimum required length in searching evidence of climatic change

*Corresponding author: Win Win Zin, Department of Civil Engineering, Yangon Technological University, Insein Rd, Yangon, Myanmar, Tel: 9595003274; E-mail: winwinzin@ytu.edu.mm

Received March 12, 2017; Accepted April 12, 2017; Published April 18, 2017

Citation: Zin WW, Rutten M (2017) Long-term Changes in Annual Precipitation and Monsoon Seasonal Characteristics in Myanmar. Hydrol Current Res 8: 271. doi: 10.4172/2157-7587.1000271

Copyright: $\odot 2017$ Zin WW, et al. This is an open-access article distributed under the terms of the Creative Commons Attribution License, which permits unrestricted use, distribution, and reproduction in any medium, provided the original author and source are credited. 


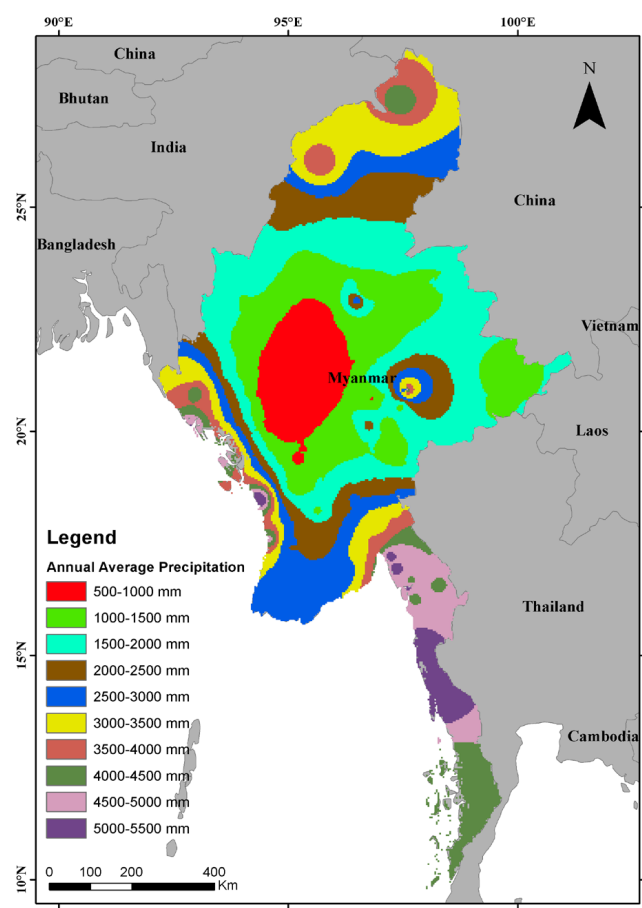

Figure1: Mean annual precipitation of Myanmar. Isohyets are developed based on average annual precipitation of two decades (1990-2010).

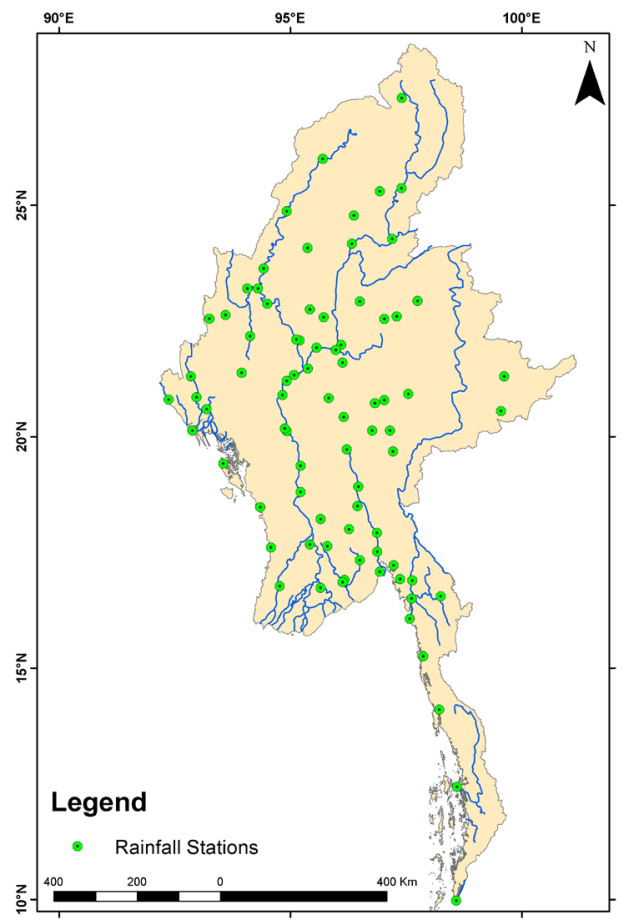

Figure 2: Monitoring network used in this study. in hydro-climatic time series, which is 25 years [14]. More specifically, 60 out of 82 stations have a sample size between 41 and 49 years, and the remaining stations have a sample size between 30 and 40 years. Monsoon onset and withdrawal dates were collected from the department of Meteorology and Hydrology in Myanmar (DMH).

\section{Pettitt test for change point analysis}

As a nonparametric test that allows detection of changes in the mean (median) when the change point time is unknown, the Pettitt test [15] has been suggested by Villarini et al. [13] to analyze the change point. This test is based on a version of the Mann-Whitney statistic for testing whether the two samples $\mathrm{X}_{1}, \ldots ., \mathrm{X}_{\mathrm{t}}$ and $\mathrm{X}_{\mathrm{t}+1}, \ldots . ., \mathrm{X}_{\mathrm{T}}$ come from the same population. The test statistic $\mathrm{K}_{\mathrm{T}}$ is defined as

$$
\mathrm{K}_{\mathrm{T}}=\max \left|\mathrm{U}_{\mathrm{t}, \mathrm{T}}\right|=\max _{1 \leq \mathrm{t} \leq \mathrm{T}}\left(\mathrm{K}_{\mathrm{T}}^{+}, \mathrm{K}_{\mathrm{T}}^{-}\right)
$$

$$
\text { Where } U_{t, T}=\sum_{i=1}^{t} \sum_{j=t+1}^{T} \operatorname{Sgn}\left(X_{i}-X_{j}\right)
$$

The $\mathrm{p}$ value of the test statistic is computed using the limiting distribution approximated by Pettitt [15], which is valid for continuous variables [13]. And the $95 \%$ confidence level was used to evaluate the significance of change points. The significant level is determined approximately by

$$
\mathrm{p}=\exp \left(\frac{-6 \mathrm{k}_{\mathrm{T}}^{2}}{\mathrm{~T}^{3}+\mathrm{T}^{2}}\right)
$$

\section{Mann-Kendall test for trend detection}

The Mann-Kendall (MK) statistical test $[16,17]$ is a non-parametric, rank based test for monotonic trend detection [18-20]. It is widely used and recommended by the World Meteorological Organization [20,21] for trend detection because it is more robust against false trend detection due to non-normally distributed time series than its parametric alternatives, yet nearly as powerful.

A critical assumption, when considering precipitation, is that elements in the time series are assumed to be independent. Several authors $[22,23]$ investigated the sensitivity of the MK test to serial correlations and proposed procedures to reduce the effect of serial correlation. Long term persistence can induce a statistically significant trend even though no trend is present. We followed the procedures described in Partal et al. [8] and first removed any lag-1 serial correlations over $5 \%$ significance level before applying the MannKendall test. The Mann-Kendall test returns the significance level of a monotonic trend. The magnitude of the trend was calculated with Sen's estimator, also following procedures described in Partal et al. [8].

\section{Results on Annual Precipitation Analysis}

\section{Results on change point analysis}

Thirteen stations show step change with a confidence over 95\% in total annual total precipitation (Table 1) and twelve in annual maximum precipitation (Table 2). Four abrupt changes happened from 1981 to 1990, seven from 1991 to 2000, two from 2001 to 2010 in the analysis of annual total precipitation. Five abrupt changes happened from 1981 to 1990, five from 1991 to 2000, two from 2001 to 2010 in the analysis of annual maximum precipitation.

An abrupt change in annual total precipitation at Kyaukphyu was 


\begin{tabular}{|c|c|c|c|c|}
\hline \multirow{2}{*}{ Station } & \multicolumn{4}{|c|}{ Pettitt test for change point } \\
\cline { 2 - 5 } & $\mathbf{K}_{\mathbf{T}}$ & $\mathbf{t}$ & $\mathbf{s h i f t}$ & $\mathbf{p}$ \\
\hline Kalaewa & 294 & 2001 & + & 0.01 \\
\hline Kawthaung & 294 & 1993 & + & 0.014 \\
\hline Kyaikkame & 180 & 2000 & + & 0.002 \\
\hline Kyaukme & 185 & 1991 & - & 0.011 \\
\hline Kyaukphyu & 368 & 1989 & + & 0.001 \\
\hline Loikaw & 248 & 2000 & + & 0.033 \\
\hline Magway & 336 & 1994 & + & 0.003 \\
\hline Maubin & 256 & 1988 & + & 0.049 \\
\hline Myeik & 266 & 1993 & + & 0.014 \\
\hline Myitkyina & 254 & 1983 & + & 0.048 \\
\hline Naungcho & 187 & 1999 & + & 0.011 \\
\hline Pinlaung & 275 & 2001 & + & 0.019 \\
\hline Sittwe & 261 & 1989 & + & 0.016 \\
\hline
\end{tabular}

Table 1: Results of Pettitt test for annual total precipitation.

\begin{tabular}{|c|c|c|c|c|}
\hline \multirow{2}{*}{ Station } & \multicolumn{4}{|c|}{ Pettitt test for change point } \\
\cline { 2 - 5 } & $\mathbf{K}_{\mathbf{T}}$ & $\mathbf{t}$ & shift & $\mathbf{p}$ \\
\hline Bhamo & 256 & 1989 & + & 0.043 \\
\hline Chauk & 223 & 1995 & - & 0.034 \\
\hline Gwa & 134 & 1992 & + & 0.028 \\
\hline Kawthaung & 348 & 1981 & + & 0.002 \\
\hline Kyauktaw & 160 & 1994 & - & 0.042 \\
\hline Maungdaw & 199 & 2007 & + & 0.039 \\
\hline Mingaladon & 268 & 2003 & + & 0.012 \\
\hline Minkin & 317 & 1995 & + & 0.001 \\
\hline Myitkyina & 281 & 1983 & + & 0.02 \\
\hline Pinlaung & 293 & 1990 & + & 0.011 \\
\hline Thandwe & 238 & 1987 & + & 0.047 \\
\hline Theinzayat & 231 & 1993 & + & 0.009 \\
\hline
\end{tabular}

Table 2: Results of Pettitt test for annual maximum precipitation.

detected to have occurred around 1989. The mean level significantly shifted upward from $4281 \mathrm{~mm}$ in the period (1967-1989) to $5013 \mathrm{~mm}$ in the period (1990-2015) as can be viewed in Figure 3. An abrupt change in annual total precipitation at Kawthaung was detected to have occurred around 1993. The mean value significantly shifted upward from $3889 \mathrm{~mm}$ in the period (1967-1993) to $4470 \mathrm{~mm}$ in the period (1994-2015) as can be viewed in Figure 4.

An abrupt change in annual total precipitation at Magway was detected to have occurred around 1994. The mean value significantly shifted upward from $749 \mathrm{~mm}$ in the period (1967-1994) to $947 \mathrm{~mm}$ in the period (1995-2015) as can be viewed in Figure 5.

An abrupt change in annual total precipitation at Sittwe was detected to have occurred around 1989. The mean value significantly shifted upward from $4423 \mathrm{~mm}$ in the period (1967-1989) to $5032 \mathrm{~mm}$ in the period (1990-2015) as can be viewed in Figure 6.

An abrupt change in annual maximum precipitation at Chauk as detected to have occurred around 1995. The mean value significantly shifted downward from $86 \mathrm{~mm}$ in the period (1967-1995) to $62 \mathrm{~mm}$ in the period (1996-2015) as can be viewed in Figure 7. An abrupt change in annual maximum precipitation at Myitkyina was detected to have occurred around 1983. The mean value significantly shifted upward from $108 \mathrm{~mm}$ in the period (1967-1983) to $141 \mathrm{~mm}$ in the period (19842015) as can be viewed in Figure 8.

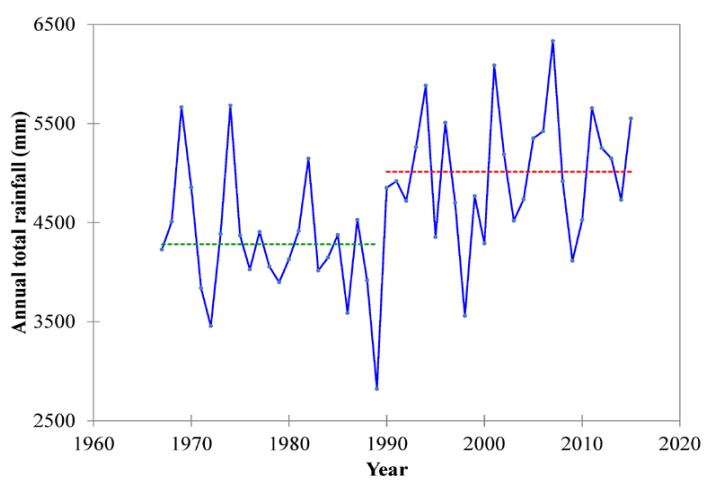

Figure 3: Change of mean value in Kyaukphyu before and after change point.

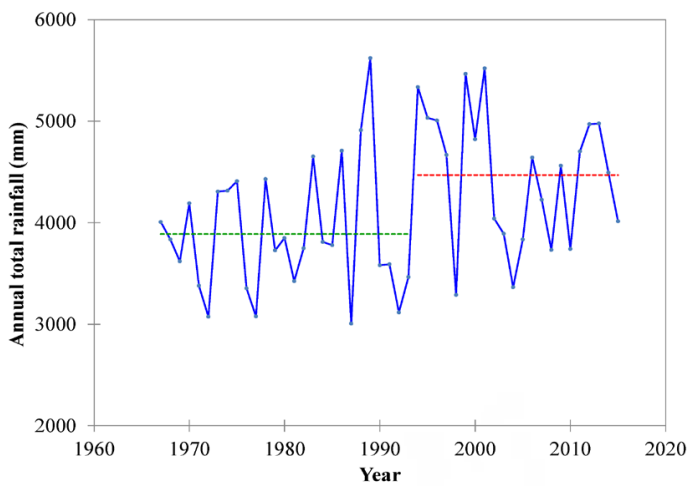

Figure 4: Change of mean value in Kawthaung before and after change point.

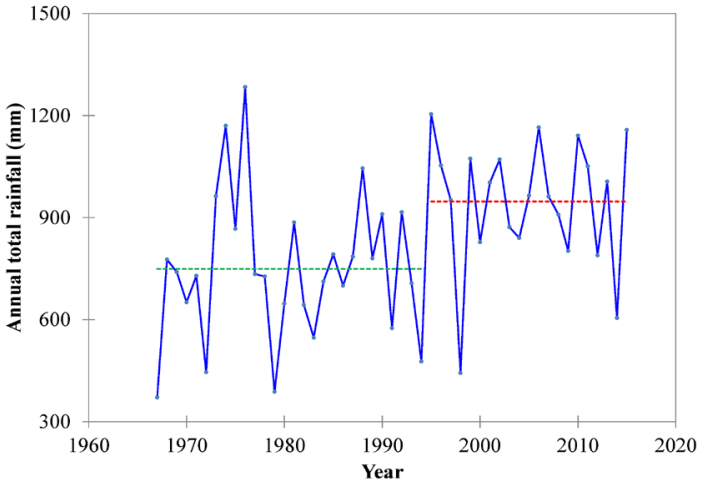

Figure 5: Change of mean value in Magway before and after change point

\section{Results on trend analysis}

The Mann-Kendall method was applied to time series from the selected precipitation stations. All trend results in this research have been evaluated at $10 \%$ level of significance to ensure an effective exploration of the trend characteristics of the study region. Significance level indicates the trend's strength and Sen's slope estimator indicates the magnitude of the trend. We considered the lag 1 serial correlation 
Page 4 of 8

before applying the Mann-Kendall test for the significance of the trend. 75 stations do not show significant serial correlation in annual total precipitation series and 80 stations do not show significant serial correlation in annual maximum precipitation series.

Table 3 shows results of trend analysis under monotonic trend assumption. Among 82 stations, the number of stations containing a positive trend in annual precipitation is 54 and the number containing a negative trend is 28 .

Results of detected stations (significance level less than 10\%) are described in Tables 4 and 5 respectively. Among 82 stations, 17 stations showed a significant trend, the remaining 65 stations showed no significant trend in annual total precipitation. Among the 17 stations with significant trends, fourteen stations (Kalaewa, Kawthaung, Kyaikkame, Kyaukphyu, Kyauktaw, Lashio, Magway, Maubin, Mawlamyine, MyaukU, Myeik, Myitkyina, Yangon, Zaungtu) showed an upward trend, three stations (Chauk, Lashio and Kyaukme) displayed downward trends. Some stations were noted to have particularly strong trends. Annual total precipitation at Magway, Kyaikkame and Kyaukphyu displayed an increasing trend at $1 \%$ significance level. The strongest increasing trend was detected at the Kyaikame station $(35.2 \mathrm{~mm}$ per annual) in annual total precipitation. The strongest decreasing trend was detected at the Kyaukme station $(7.5 \mathrm{~mm}$ per annual) in annual total precipitation.

Among 82 stations, 14 stations showed a significant trend, the remaining 68 stations showed no significant trend in annual maximum precipitation. Annual maximum precipitation at Kawthaung, Kyauktaw and Minkin displayed an increasing trend at $1 \%$ significance level. The strongest increasing trend was detected at the Kyauktaw station $(3.0 \mathrm{~mm}$ per annual) in annual maximum precipitation.

Figures 9 and 10 show the spatial distribution of trends for annual total precipitation and annual maximum precipitation for the selected stations in Myanmar. The spatial distribution of the trends for the annual precipitation exhibited that downward trends were mainly detected in the central and eastern parts of the country, and adversely, in the southern and coastal parts of the country upward trends were detected at most of the stations.

Significant trends for annual total precipitation and annual maximum precipitation are shown in Figures 11 and 12 respectively.

Besides, trend has also been done for the stations with change points. Trend analysis was done separately for the subseries divided by the change points. Trends in annual total series and annual maximum series prior to and posterior to change points are shown in Tables 6 and 7 respectively. When change point are considered, only three significant trends were found in annual series.

The direction of the trends of subseries prior to and posterior to the change points was the same at five stations and adverse direction of trend was found in the subseries at the other eight stations in annual total precipitation series. At Kalaewa station, the subseries prior to the change point has decreasing trend and an increasing trend was seen after change point.

\begin{tabular}{|c|c|c|c|c|c|c|}
\hline \multirow{2}{*}{ Series } & \multicolumn{3}{|c|}{ General trends } & \multicolumn{3}{c|}{ Significant trend } \\
\cline { 2 - 7 } & Total & down & up & Total & down & up \\
\hline Annual precipitation & 82 & 28 & 54 & 17 & 3 & 14 \\
\hline Annual maximum precipitation & 82 & 28 & 54 & 14 & 2 & 12 \\
\hline
\end{tabular}

Table 3: Results of trend analysis under monotonic trend assumption.

\begin{tabular}{|c|c|c|c|c|c|c|}
\hline \multirow[t]{2}{*}{ Station } & \multicolumn{3}{|c|}{ Mann-Kendall test } & \multicolumn{3}{|c|}{$\begin{array}{l}\text { Sen's slope estimator } \\
\text { (mm/year) }\end{array}$} \\
\hline & $\mathbf{Z}$ & Trend & Significance & $\mathbf{Q}$ & $Q_{95(L)}$ & $Q_{95(U)}$ \\
\hline Chauk & -1.98 & Down & ** & -4.14 & -8.16 & -0.11 \\
\hline Kalaewa & 1.78 & up & * & 4.57 & -0.37 & 10.80 \\
\hline Kawthaung & 2.16 & Up & ** & 15.93 & 1.78 & 31.00 \\
\hline Kyaikkame & 2.62 & Up & $* * *$ & 35.26 & 11.44 & 59.99 \\
\hline Kyaukme & -2.05 & Down & ** & -7.44 & -14.36 & -0.27 \\
\hline Kyaukphyu & 2.93 & Up & $\star * *$ & 19.64 & 8.33 & 33.57 \\
\hline Kyauktaw & 2.49 & Up & ** & 31.36 & 7.09 & 54.23 \\
\hline Lashio & -2.08 & Down & * & -4.20 & -8.01 & 0.64 \\
\hline Magway & 2.77 & Up & 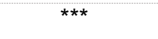 & 6.42 & 2.58 & 10.94 \\
\hline Maubin & 2.24 & Up & ** & 8.54 & 1.32 & 17.38 \\
\hline Mawlamyine & 1.83 & Up & * & 14.26 & -1.71 & 29.57 \\
\hline MyaukU & 1.92 & up & * & 21.61 & -0.37 & 42.22 \\
\hline Myeik & 2.12 & Up & ** & 11.13 & 2.00 & 19.58 \\
\hline Myitkyina & 1.96 & Up & ** & 7.23 & 0.13 & 14.08 \\
\hline Naungcho & 1.89 & Up & * & 6.68 & -0.24 & 11.69 \\
\hline Yangon & 1.77 & Up & * & 5.63 & -0.86 & 13.44 \\
\hline Zaungtu & 2.38 & Up & $* *$ & 22.96 & 6.34 & 40.13 \\
\hline
\end{tabular}

Table 4: Results of Mann-Kendall Test with Sen's slope estimator for annual total precipitation by ignoring the presence of change points.

$$
\begin{aligned}
* \quad \alpha & =0.1 \text { level of significance } \\
* * \quad \alpha & =0.05 \text { level of significance } \\
* * * \quad \alpha & =0.01 \text { level of significance }
\end{aligned}
$$

The direction of trends of subseries prior to and posterior to the change point was the same at six stations and adverse direction of trend was found in the subseries at the other four stations in annual maximum precipitation series.

\begin{tabular}{|c|c|c|c|c|c|c|}
\hline \multirow{2}{*}{ Station } & \multicolumn{3}{|c|}{ Mann-Kendall test } & \multicolumn{3}{c|}{$\begin{array}{c}\text { Sen's slope estimator } \\
\text { (mm/year) }\end{array}$} \\
\cline { 2 - 7 } & $\mathbf{Z}$ & Trend & Significance & $\mathbf{Q}$ & $\mathbf{Q}_{95(\mathrm{~L})}$ & $\mathbf{Q}_{95(\mathbf{U})}$ \\
\hline Bhamo & 1.84 & Up & $*$ & 0.68 & 0.05 & 1.53 \\
\hline Gwa & 2.11 & Up & $* *$ & 2.71 & 0.29 & 5.18 \\
\hline Katha & 1.92 & Up & $*$ & 0.72 & 0 & 1.39 \\
\hline Kawthaung & 2.58 & Up & $* * *$ & 1.06 & 0.3 & 2.13 \\
\hline Kyaukphyu & 1.86 & Up & $*$ & 1.2 & -0.04 & 2.55 \\
\hline Kyauktaw & 3.59 & Up & $* *$ & 3.03 & 1.55 & 4.68 \\
\hline Maungdaw & 2.36 & Up & $* *$ & 2.13 & 0.57 & 4.0 \\
\hline Mingaladon & 2.44 & Up & $* *$ & 0.76 & 0.11 & 1.37 \\
\hline Minkin & 2.81 & Up & $* *$ & 1.12 & 0.42 & 2.37 \\
\hline Phyu & -1.74 & Down & $*$ & -0.87 & -1.8 & 0.17 \\
\hline Pinlaung & 1.71 & Up & $*$ & 0.35 & -0.05 & 0.81 \\
\hline Pyinmana & -1.77 & Down & $*$ & -0.37 & -0.89 & 0.03 \\
\hline Theinzayat & 1.85 & Up & $*$ & 1.0 & -0.05 & 2.0 \\
\hline Thandwe & 1.75 & Up & $*$ & 1.23 & -0.13 & 2.48 \\
\hline
\end{tabular}

Table 5: Results of Mann-Kendall Test with Sen's slope estimator for annual maximum precipitation by ignoring presence of change points. 


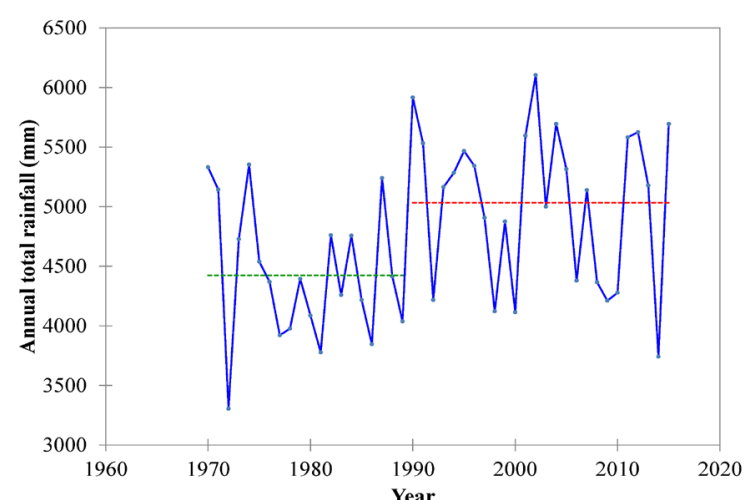

Figure 6: Change of mean value in Sittwe before and after change point.

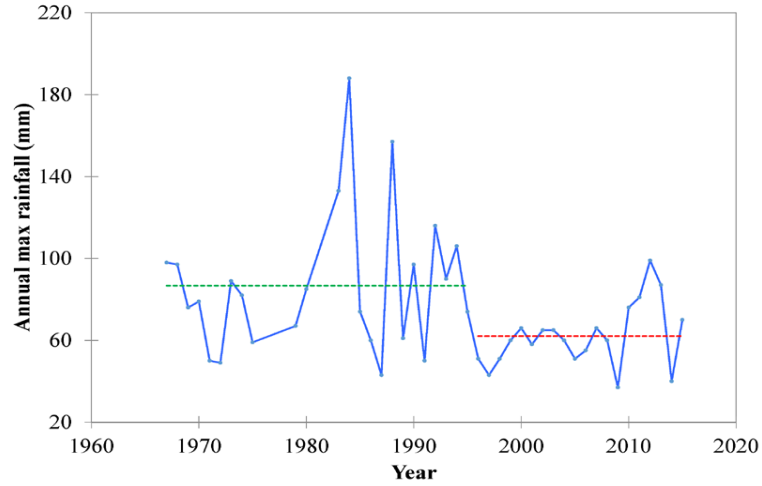

Figure 7: Change of mean value in Chauk before and after the change point.

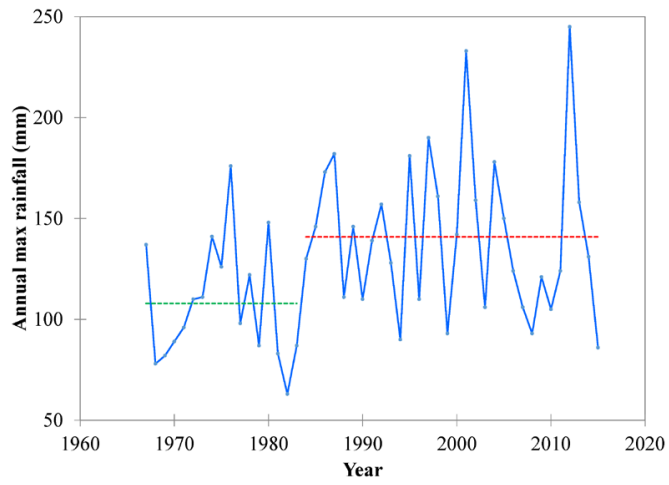

Figure 8: Change of mean value in Myitkyina before and after change point.

\section{Results on southwest monsoon onset and withdrawal analysis}

In addition to trends in annual total and annual maximum precipitation, trends in monsoon onset and withdrawal were investigated. Monsoon onset and withdrawal days were collected from the Department of Meteorology and Hydrology (DMH). Due to late

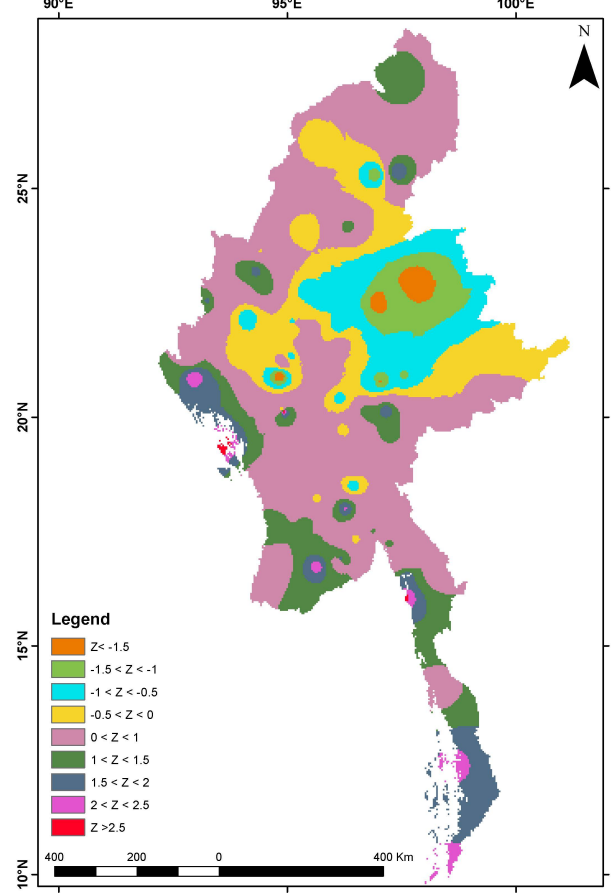

Figure 9: Spatial distribution of trends for annual total precipitation.

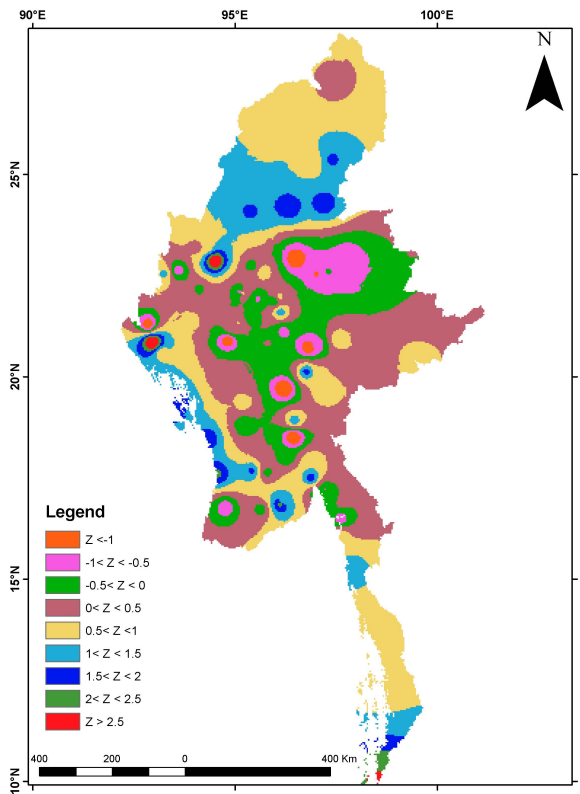

Figure 10: Spatial distribution of trends for annual maximum precipitation

onset and early withdrawal of the monsoon, the duration of monsoon has become shorter in last three decades.

Results of Mann-Kendall test for monsoon time series over the period 1967-2015 are shown in Table 8. Monsoon duration and withdrawal days displayed a significant decreasing trend. 
Page 6 of 8

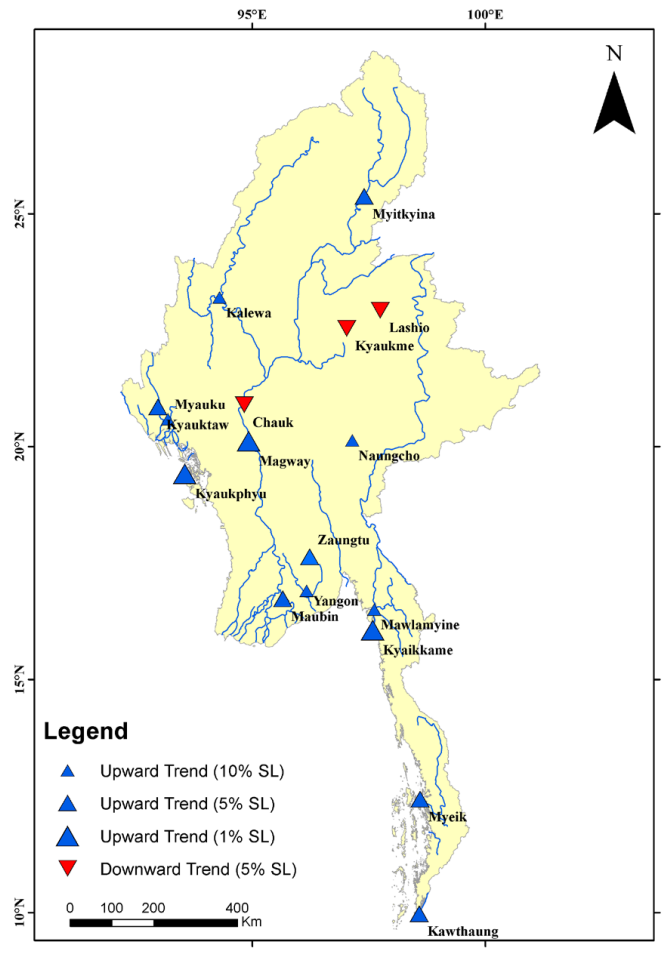

Figure 11: Significant trends for annual total precipitation

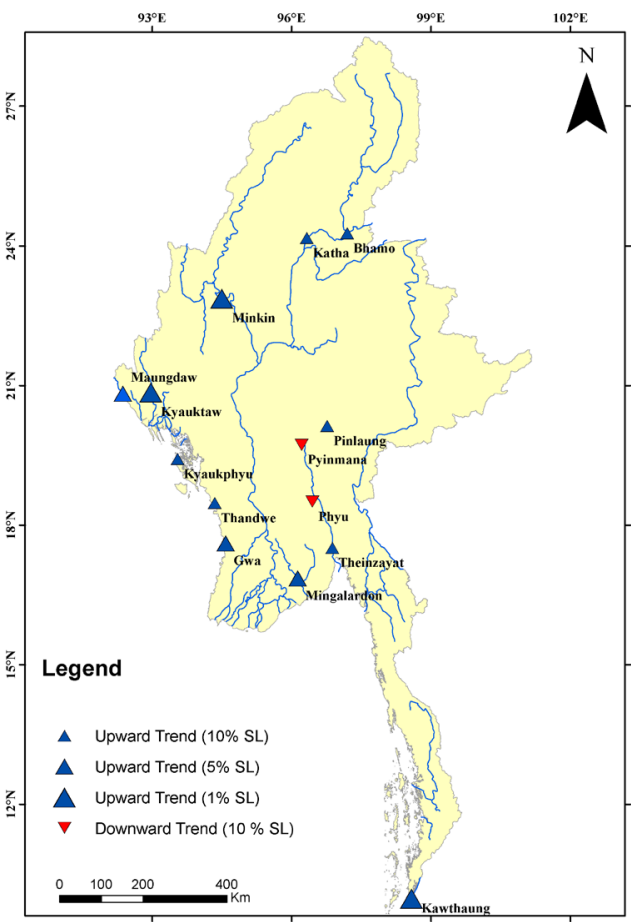

Figure 12: Significant trends for annual maximum precipitation

\begin{tabular}{|c|c|c|c|c|c|}
\hline \multirow{2}{*}{ Station } & \multirow{2}{*}{ Change point } & \multicolumn{2}{|c|}{ prior to change points } & \multicolumn{2}{|c|}{$\begin{array}{c}\text { posterior to change } \\
\text { points }\end{array}$} \\
\cline { 3 - 6 } & & $\mathbf{Z}$ & direction & $\mathbf{Z}$ & direction \\
\hline Kalaewa & 2001 & -1.73 & - & 1.68 & + \\
\hline Kawthaung & 1993 & 0.04 & + & -0.69 & - \\
\hline Kyaikkame & 2000 & -0.14 & - & 0.2 & + \\
\hline Kyaukme & 1991 & 1.03 & + & -0.21 & - \\
\hline Kyaukphyu & 1989 & -1.37 & - & 1.17 & + \\
\hline Loikaw & 2000 & -1.73 & - & 0.88 & + \\
\hline Magway & 1994 & 0.1 & + & 0 & + \\
\hline Maubin & 1988 & 0 & + & 0.26 & + \\
\hline Myeik & 1993 & -1.31 & - & 0.79 & + \\
\hline Myitkyina & 1983 & -0.95 & - & 0.26 & + \\
\hline Naungcho & 1999 & -0.23 & - & -0.77 & - \\
\hline Pinlaung & 2001 & -1.19 & - & -0.11 & - \\
\hline Sittwe & 1989 & -1.01 & - & -0.06 & - \\
\hline & & & & & + \\
\hline
\end{tabular}

Table 6: Trends in annual total precipitation series prior to and posterior to change points (The bold values denote $90 \%$ confidence level)

\begin{tabular}{|c|c|c|c|c|c|}
\hline \multirow{2}{*}{ Station } & \multirow{2}{*}{ Change point } & Prior to change points & \multicolumn{2}{|c|}{$\begin{array}{c}\text { Posterior to } \\
\text { change points }\end{array}$} \\
\cline { 3 - 6 } & & $\mathbf{Z}$ & Direction & $\mathbf{Z}$ & Direction \\
\hline Bhamo & 1989 & -0.61 & - & 0.02 & + \\
\hline Chauk & 1995 & 0.3 & + & 1.55 & + \\
\hline Kawthaung & 1981 & 0.2 & + & -0.58 & - \\
\hline Kyauktaw & 1994 & 1.15 & + & 0.88 & + \\
\hline Mingaladon & 2003 & -0.18 & - & 0.86 & + \\
\hline Minkin & 1995 & -0.82 & - & 1.85 & + \\
\hline Myitkyina & 1983 & -0.18 & - & -0.02 & - \\
\hline Pinlaung & 1990 & -0.9 & - & -0.72 & - \\
\hline Theinzayat & 1993 & -0.21 & - & -0.87 & - \\
\hline Thandwe & 1987 & -0.76 & - & -0.09 & - \\
\hline
\end{tabular}

Table 7: Trends in annual maximum precipitation series prior to and posterior to change points (The bold values denote $90 \%$ confidence level)

The results of Pettitt test for monsoon time series over the period 1967-2015 are shown in Table 9. The monsoon duration was about 135 days before 1988 and 120 days after 1988. It was observed that monsoon duration and withdrawal days have shifted significantly according to the Pettit test $(\mathrm{p}=0.95)$. Moreover, it was noticed that monsoon withdrawal dates have shifted to be early. The change of mean value in monsoon withdrawal and monsoon duration are shown in Figures 13 and 14. 


\begin{tabular}{|l|c|c|}
\hline \multirow{2}{*}{} & \multicolumn{2}{|c|}{ Mann-Kendall test } \\
\cline { 2 - 3 } & $\mathbf{Z}$ & Significance \\
\hline Monsoon duration & -2.29 & $5 \% \mathrm{SL}$ \\
\hline Withdrawal days & -3.15 & $1 \% \mathrm{SL}$ \\
\hline Onset days & 1.16 & No significant \\
\hline
\end{tabular}

Table 8: Results of Mann-Kendall test for monsoon analysis.

\begin{tabular}{|c|c|c|c|c|}
\hline \multirow{2}{*}{} & \multicolumn{3}{|c|}{} \\
\cline { 2 - 5 } & $\mathbf{K}_{\mathrm{T}}$ & $\mathbf{t}$ & shift & $\mathbf{p}$ \\
\hline Monsoon duration & $\mathbf{3 5 9}$ & $\mathbf{1 9 8 8}$ & - -(shorter) & $\mathbf{0 . 0 0 2 6}$ \\
\hline Monsoon withdrawal & $\mathbf{4 5 8}$ & $\mathbf{1 9 8 9}$ & - (earlier) & $\mathbf{0 . 0 0 0 1}$ \\
\hline Monsoon onset & 191 & 1976 & & 0.238 \\
\hline
\end{tabular}

Table 9: Results of Pettitt test for monsoon time series (Data series with significant shifts at 0.05 significance level are shown in bold).

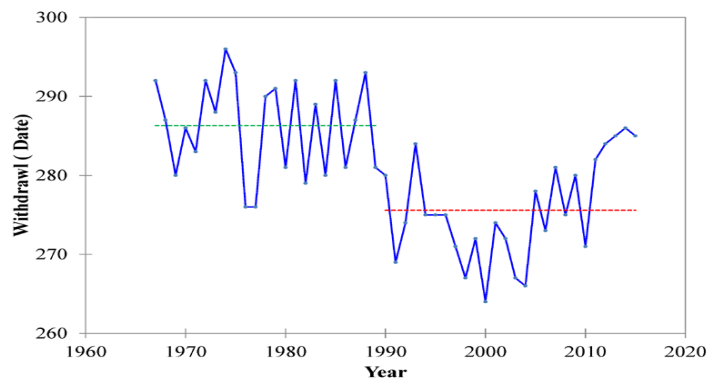

Figure 13: Change of mean value in monsoon withdrawal before and after the change point.

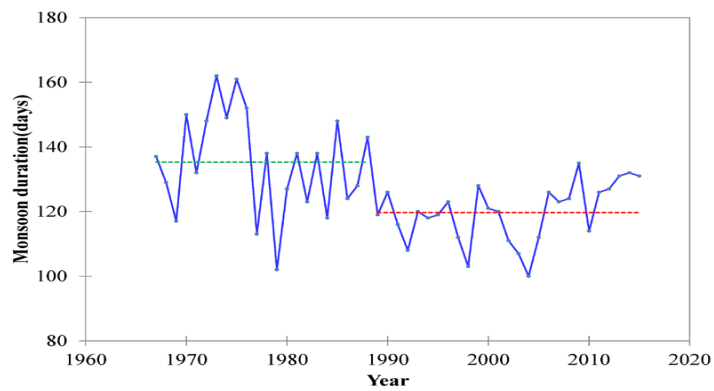

Figure 14: Change of mean value in monsoon duration before and after change point.

\section{Discussion}

We detected some significant changes in precipitation in Myanmar over the last few decades. Significant trends were obtained if the absence of change points was assumed; however, mostly no significant trends were obtained in the subseries divided by the change points. Thus, abrupt behavior of the time series should be taken into account in trend analysis, or else, results of trends could be misleading. Subseries after the change point analysis are considered short for the trend detection, hence the results of trend for the sub-series at some stations may not be robust.
According to Wang et al. [5], global warming has led to cyclone intensification particularly in the pre-monsoon season which has led to increase in overall precipitation. An intensification of the monsoon the shorter monsoon season is also reported by the Myanmar Department of Meteorology and Hydrology (DMH).

Wang et al. [5] hypothesize a regime shift from apparent mid latitude circulation regime to a tropical/monsoonal one in the premonsoon as an explanation for the sudden increase in precipitation in the 1990s. Changes might also be partly attributed to multi decadal modes of variability rather than one directional climate change. D'Arrigo et al. [24] show based on an analysis of teak ring data that there are significant decadal to multi decadal modes of variability that can be linked to monsoon precipitation. They suggest that these modes reflect the remote influence of the Pacific Decadal Oscillation and related regime shifts, and their impact on monsoon precipitation.

In addition to the external climate change factors mentioned above, land use changes in Myanmar may have caused significant changes in precipitation patterns. Feddema et al. [25] demonstrated the effect of land use changes on climate and specifically the Asian monsoon. Large scale land use changes could affect both strength and timing of the monsoon yet effects were different for the different change scenarios used. In Myanmar deforestation has been the major land use change so far. Over the period from 1990 to 2000 forests have declined by $0.3 \%$ annually [26] and rates have most probably been increasing since due to the faster economic development. The trend attribution and the relation between the observed precipitation trends and climate change should be addressed in future modeling and data analysis studies.

\section{Conclusion}

The paper presents an analysis of trends in precipitation in Myanmar based on long term historical station data. On the basis of annual precipitation at 82 stations in Myanmar, the long-term monotonic trend and abrupt changes have been investigated. This study performs a simultaneous evaluation of gradual and abrupt changes in annual precipitation in Myanmar using Mann-Kendall trend test and Pettitt change-point test. The application of a trend detection framework resulted in the identification of some significant trends under monotonic trend assumption. The results of Mann-Kendall analysis indicated that 17 stations have significant trend in annual total precipitation, 14 with upward trend and 3 with downward trend, the other 65 stations have no significant trend. Fourteen stations have significant trend in annual maximum precipitation, 12 with upward trend and 2 with downward trend, the other 68 stations have no significant trend.

The direction of precipitation trend was, in general, upward across the country though not statistically significant for all stations. Upward trends were mainly detected in the southern and coastal parts of the country and downward trend was mainly in the central part of the country. The shift analysis based on Pettitt test, performed in order to highlight the possible change points, showed probable change years in the decades 1980-1990 and 1990-2000 for annual precipitation.

There are 17 out of 82 stations that were dominated by significant trend in annual total precipitation series when ignoring the presence of change points. Only three significant trends were detected by considering change points in annual total precipitation series. There are 14 out of 82 stations that were dominated by significant trend in annual maximum precipitation series when ignoring the presence of change point. 
Citation: Zin WW, Rutten M (2017) Long-term Changes in Annual Precipitation and Monsoon Seasonal Characteristics in Myanmar. Hydrol Current Res 8: 271. doi: 10.4172/2157-7587.1000271

Only one statistically significant trend was detected by considering change points in annual maximum precipitation series. Therefore, a study of monotonic trends in a time series regardless of the abrupt shifts in mean or change in direction of trends can lead to misleading conclusions.

In addition, a clear shift in the monsoon duration and withdrawal dates was detected. Onset dates were delayed and withdrawal dates were advanced leading to a shortening of the monsoon seasons. The trend attribution and the relation between the observed precipitation trends and climate change should be addressed in future studies with the inclusion of the influence of temperature.

Changes in precipitation lead to changes in runoff and water availability that can be critical in the fast-developing country Myanmar, especially in more dry regions. It is important to investigate present and probable future climatic change patterns and their impacts on water resources so that appropriate adaptation strategies may be implemented.

\section{References}

1. Taft L, Evers M (2016) A review of current and possible future human-water dynamics in Myanmar's river basins. Hydrological Earth System Science 20: 4913-4928.

2. Kar AK, Winn LL, Lohani AK, Goel NK (2011) Soft computing-based workable flood forecasting model for Ayeyarwady River Basin of Myanmar. Journal of Hydrologic Engineering 17: 807-822.

3. Trenberth KE (2011) Changes in precipitation with climate change. Climate Research 47: 123

4. Sen Roy N, Kaur S (2000) Climatology of monsoon rains of Myanmar (Burma). Int J Climatol 20: 913-928.

5. Wang SY, Buckley BM, Yoon, JH, Fosu B (2013) Intensification of premonsoon tropical cyclones in the Bay of Bengal and its impacts on Myanmar. Journal of Geophysical Research: Atmospheres 118: 4373-4384.

6. Turner AG, Annamalai H (2012) Climate change and the South Asian summer monsoon. Nature Climate Change 2: 587-595.

7. Htut AY, Shrestha S, Nitivattananon V, Kawasaki A (2014) Forecasting Climate Change Scenarios in the Bago River Basin, Myanmar. J Earth Sci Clim Change 5: 228

8. Partal T, Kahya E (2006) Trend analysis in Turkish precipitation data. Hydrological Processes 20: 2011-2026.

9. Li ZL, Xu ZX, Li JY (2008) Shift trend and step changes for runoff time series in the Shiyang River basin, northwest China. Hydrological Process 22: 46394646 .
10. Hirsch RM, Slack JR, Smith RA (1982) Techniques of trend analysis for monthly water quality data. Water Resources Research 18: 107-121.

11. Xu ZX, Takeuchi K, Ishidaira H (2003) Monotonic trend and step changes in Japanese precipitation. Journal of Hydrology 279: 144-150.

12. Xu ZX, Takeuchi K, Ishidaira H, Li J (2005) Long-term trend analysis for precipitation in Asian Pacific FRIEND river basins. Hydrological Processes 19: 3517-3532.

13. Villarini G, Serinaldi F, Smith AJ, Krajewski FW (2009) On the stationarity of annual flood peaks in the continental United States during the 20th century. Water Resour Res 45: W08417.

14. Burn HB, Elnur MAH (2002) Detection of hydrologic trends and variability Journal of Hydrology 255: 107-122.

15. Pettitt AN (1979) A non-parametric approach to the change-point problem. App Stat 28: 126-135.

16. Mann HB (1945) Nonparametric tests against trend. Econometrica 13: 245-259.

17. Kendall MG (1948) Rank Correlation Methods. Hafner, New York, USA.

18. Helsel DR, Hirsch RM (1992) Statistical Methods in Water Resources. Elsevier, Amsterdam.

19. Serrano A, Mateos VL, Garcia JA (1999) Trend analysis of monthly precipitation over the iberian peninsula for the period 1921-1995. Physics and Chemistry of the Earth, Part B: Hydrology, Oceans and Atmosphere. 24: 85-90.

20. Yue S, Pilon P, Phinney B, Cavadias G (2002) The influence of autocorrelation on the ability to detect trend in hydrological series. Hydrological Processes 16 : 1807-1829.

21. Mitchell JM, Dzerdzeevskii B, Flohn H, Hofmeyr, WL, Lamb HH, et al. (1966) Climatic change. (Report of a working group of the Commission for Climatology) WMO Technical Note No. 79. World Meteorological Organization, p: 79.

22. Hirsch RM, Slack JR (1984) A nonparametric trend test for seasonal data with serial dependence. Water Resources Research 20: 727-732.

23. Kulkarni A, Von Storch H (1995) Monte-Carlo experiments on the effect of seria correlation on the Mann-Kendall test of trend. Meteorologische Zeitschrift 4: $82-85$

24. D'Arrigo R, Ummenhofer CC (2015) The climate of Myanmar: evidence for effects of the Pacific decadal oscillation. Int J Climatol 35: 634-640

25. Feddema JJ, Oleson KW, Bonan GB, Mearns LO, Buja LE, et al. (2005) The importance of land-cover change in simulating future climates. Science 310 1674-1678.

26. Leimgruber P, Kelly DS, Steininger MK, Brunner J, Müller T, Songer M (2005) Forest cover change patterns in Myanmar (Burma) 1990-2000. Environmental Conservation 32: 356-364. 